\title{
Educação Ambiental crítica e arte participativa: a construção de reflexão e ação em uma escola da Baixada Fluminense
}

Critical Environmental Education and participatory art: the construction of reflection and action in a school in the Baixada Fluminense

\author{
Luciana Simões Rodrigues Nunes ${ }^{1}$ \\ Alexandre Maia do Bomfim ${ }^{2}$ \\ Giselle Roças de Souza Fonseca ${ }^{3}$
}

\section{Resumo}

Este artigo integra parte de uma pesquisa maior intitulada "Educação Ambiental e Arte Participativa: questões socioambientais através da sensibilidade e criticidade". Aqui, apresenta uma reflexão sobre as contribuições que a Educação Ambiental Crítica associada à arte participativa pode trazer para a formação específica de estudantes, no que se refere à temática ambiental. O contorno desta investigação se deu por meio de uma prática que uniu elementos cognitivos e afetivos, a partir da análise de questões locais, promovendo a participação coletiva e cooperativa dos envolvidos, a partir da experiência estética e da capacidade questionadora. A metodologia caracterizou-se por uma abordagem qualitativa, com os princípios de uma pesquisa participante, aplicada em duas turmas de ensino médio de uma escola estadual da Baixada Fluminense, num intervalo de três meses. Foram utilizados dois instrumentos para a coleta de dados - observação e desenhos produzidos pelos alunos - que possibilitaram analisar as representações e a imaginação dos educandos sobre o ambiente que os cerca. Avaliando as atividades e produções ao longo deste trabalho, levamos os alunos para uma observação crítica de seu ambiente, sob uma perspectiva social e histórica, promovendo um aprendizado com significativo potencial de transformação, deslocando conteúdos, que normalmente são abordados de forma generalista e descontextualizada, para a realidade dos educandos.

Palavras chave: ciência e arte; educação ambiental crítica; ensino médio; educação ambiental e arte.

\section{Abstract}

This article integrates part of a larger research entitled "Environmental Education and Participatory Art: social-environmental issues through sensitivity and criticality". Here, it

\footnotetext{
${ }^{1}$ Secretaria de Estado de Educação do Rio de Janeiro | lucianasrnunes@hotmail.com

2 Instituto Federal de Educação, Ciência e Tecnologia do Rio de Janeiro | alexandre.bomfim@ifrj.edu.br

${ }^{3}$ Instituto Federal de Educação, Ciência e Tecnologia do Rio de Janeiro | giselle.rocas@ifrj.edu.br
} 
presents a reflection on the contributions that the Environmental Critical Education associated with the participatory art can bring to the specific formation of students, in what refers to the environmental theme. The outline of this investigation was through a practice that linked cognitive and affective elements, from the analysis of local issues, promoting the collective and cooperative participation of those involved, based on aesthetic experience and questioning capacity. The methodology was characterized by a qualitative approach, with the principles of a participant research, applied in two high school classes of a state school of Baixada Fluminense, in an interval of three months. Two instruments were used to collect data - observation and drawings produced by the students - that made it possible to analyze the representations and the imagination of the students about the environment that surrounds them. Evaluating the activities and productions throughout this work, we take the students to a critical observation of their environment, from a social and historical perspective, promoting a learning with significant transformation potential, displacing contents, which are usually approached in a generalist and decontextualized way, to the reality of learners.

Keywords: science and art; critical environmental education; high school; environmental education and art.

\section{Introdução}

É povo na arte

É arte no povo

E não o povo na arte

De quem faz arte com o povo

(Nação Zumbi)

O presente artigo levanta a importância de uma educação com abordagem crítica e estética. Seguindo os preceitos de uma Educação Ambiental Crítica (EA-Crítica), propomos a questão da sensibilidade como ponto de partida, pois sustentamos uma relação entre Educação Ambiental, estética e arte, de modo a alcançar uma Educação Ambiental que considere também a afetividade. Nossa pesquisa foi delineada por uma prática que uniu esses elementos cognitivos e afetivos, onde a abordagem da temática ambiental se deu a partir da análise de questões locais, com atividades artísticas fundamentadas na dialogicidade e participação cooperativa dos envolvidos.

Uma Educação Ambiental Crítica deve destrinchar as causas que levam à degradação socioambiental no ambiente em que o educador está atuando, evidenciando que, apesar das particularidades de cada território, em cada um deles são indissociáveis as questões ambientais locais das sociais a que as populações são expostas. Layrargues (2000) afirma que muitos educadores ainda fazem confusão conceitual entre o domínio de uma educação conservacionista e a educação ambiental, pois normalmente é dada uma atenção maior às consequências do que às causas de um dado fenômeno. $O$ autor critica a educação preservacionista por se deter a uma perspectiva tecnocrática, onde soluções apresentadas estão apoiadas apenas em tecnologias adequadas ou supostamente não nocivas ao ambiente.

A Educação Ambiental Crítica não descarta a importância de soluções técnicas para questões ambientais, assim como não é contrária a mudanças de hábitos individuais que 
colaborem com a conservação ambiental. Tecnologias que gerem menos impactos e ações individuais em prol da conservação devem ser abordadas em uma Educação Ambiental Crítica, apenas não podem ser isentas de questionamentos políticos-ideológicos. Os educadores que se propõem a fazer Educação Ambiental devem evidenciar as verdadeiras causas da crise ambiental, nunca ficando apenas na superfície do problema. Para isso, precisamos ter em mente que qualquer ponto de vista capaz de permitir o vislumbre da conexão entre as dimensões ecológicas e as econômicas, as políticas, as sociais ou as culturais, será temido e intolerado pelos que exercem o poder de forma hegemônica, pois "abrem horizontes infinitesimais" (BARCHI, 2009, p. 184) e porque vão de encontro às perspectivas modeladoras e uniformizantes. Propomos uma experiência estética, onde a percepção é acompanhada de uma sensibilidade criativa que conduz o indivíduo a ampliar seu olhar para novas possibilidades de mundo, que permita o despertar de uma afetividade pautada por valores que priorizem uma relação harmônica com o meio. Guattari (1992) defende uma redefinição dos paradigmas estéticos sob uma nova urbanística, alicerçada no funcionamento integrado de três tipos de ecologias: mental, social e ambiental.

Consideramos que propor uma experiência estética através da arte, juntamente com a abordagem dos conflitos socioambientais na região em que a escola está inserida, pode dar início a uma reflexão crítica a respeito das questões ambientais locais. Para isso, Marin (2007, p. 116) atenta que "é necessário que se pense formas de transpor o sentido de treino artístico em que se reduziu a dimensão estética da educação e o adestramento ao apelo moralista pelas gerações futuras a que se minimizou a educação ambiental". Sob essa perspectiva, ao lado de uma EA-Crítica, defendemos uma "arte participativa", voltada para contemplação da realidade e ao estímulo da criatividade, contextualizada pelos aspectos estéticos locais, daqueles em que os estudantes (nossos sujeitos) frequentam. Optamos por utilizar o termo "arte participativa" para denominar a arte que não se restringe apenas à apreciação e que seja utilizada como forma de expressão por sujeitos diversos, desvinculada da obrigatoriedade de uma habilidade técnica estabelecida, a arte em que o processo criativo, a relação com seu entorno e com as outras pessoas sejam mais importantes que a própria obra.

\section{A Educação Ambiental considerando os aspectos sociais da Baixada Fluminense}

A Baixada Fluminense é uma região que atravessa histórico descaso socioambiental, onde grande parte da população há muito tempo carece de recursos básicos e convive com um constante cenário de violência. Simões (2006) afirma que o processo de ocupação da Baixada Fluminense, principalmente no século XX, representou uma transformação radical da configuração original de seu ambiente, onde diversas obras de engenharia levaram à retilinização de seus rios, criação de barragens e represas, desmatamento de encostas e impermeabilização do solo. O autor atenta para a necessidade de compreensão dos processos de ocupação e urbanização da Baixada Fluminense como:

(...) manifestações locais e particulares de processos mais amplos que vão das inscrições materiais do espaço das relações sociais e econômicas do capitalismo em geral no seu modelo brasileiro, até a inserção desta região no processo de metropolização do Rio de Janeiro (SIMÕES, 2006, p.5). 
O município de Queimados, lugar de nossa pesquisa, é um local que já havia sofrido com ações degradantes de atividades agrícolas extensivas até o século XIX, mas foi o histórico da urbanização que acabou por dar forma às características mais determinantes. Com a extensão da linha férrea de Nova Iguaçu a Japeri em 1951, o ritmo da ocupação na região acelerou seguindo os moldes dos outros distritos (que depois se emanciparam) da Baixada Fluminense, onde a ocupação ocorre a partir da estação, na forma de loteamentos populares com baixíssima infraestrutura e grande carência material (SIMÕES, 2006). A linha férrea que liga a Baixada Fluminense à Central do Brasil possibilita aos trabalhadores um fluxo relativamente rápido (ainda que pouco confortável) entre ambiente de trabalho e moradia, abarcando parte da população atingida pela especulação imobiliária no Rio de Janeiro.

Apesar da existência de um polo industrial no município, criado na década de 70, segundo Simões (2006), as empresas que compõem esse distrito não são grandes geradoras de empregos locais, visto que utilizam tecnologias que ao exigir mão de obra qualificada acabam não recrutando os trabalhadores da própria região. Para o autor, o modelo econômico de Queimados caracterizado pela fragilidade do comércio local, com uma atividade agropecuária quase inexistente e principalmente a baixa de articulação entre o distrito industrial e a cidade, leva o município ao baixo PIB (segundo menor da Baixada Fluminense) e reflete à composição social e às características dos grupos políticos locais:

De um lado temos um contingente de trabalhadores com baixa qualificação, pouco sindicalizados e que em Queimados são muito mais "moradores" que "trabalhadores", e por isso têm uma atuação política calcada nestas características. [...] O movimento popular de maior relevância são as associações de moradores e grupos religiosos, nem todos com caráter progressista. Assim, suas demandas estão muito mais na esfera das reivindicações por serviços e equipamentos urbanos e melhorias das condições de vida do que nas propostas de reformas sociais, econômicas e políticas de caráter estrutural (SIMÕES, 2006, p. 203).

Partindo das características socioambientais da Baixada Fluminense como um todo e de Queimados em específico, consideramos a região um terreno fértil para o desenvolvimento de pesquisas com abordagem ambiental em sua vertente crítica, visto a importância em evidenciar as contradições a que os habitantes são submetidos.

Acserald (2004) acentua a questão da desigualdade ambiental ao destacar uma característica da crença liberal, em que pessoas, espacialmente situadas em locais degradados, não teriam feito investimentos pessoais para mudar a própria realidade. Esse mesmo discurso sugere que processos de melhorias ambientais nesses locais acarretariam em uma elevação do custo de vida (moradia, imposto, transporte), resultando na "expulsão" dos pobres de seus locais de origem, o que acaba por manter esses locais em constante processo de degradação.

O espaço comum é o primeiro a manifestar os conflitos socioambientais, que na definição de Layrargues (2000) são conflitos sociais expressos em elementos da natureza e nas relações de tensão entre interesses coletivos e privados, entre espaços públicos e a tentativa de apropriação dos mesmos. É importante ressaltar que nenhum ambiente está imune de sofrer as consequências desses conflitos, porém são nos locais de maior fragilidade social que os efeitos da degradação se apresentam em sua forma mais severa. 
Para Bomfim e Piccolo (2011, p. 190) "na relação entre ricos e pobres são estes últimos que experimentam as mazelas da degradação ambiental, moram próximos a rios e baías poluídos, nas encostas desmatadas (...)" enfim, não se pode pensar a questão ambiental (nem a Educação Ambiental) sem pensar em desigualdade social, por exemplo.

Uma Educação Ambiental que apresente um processo transformador como objetivo, entre outros pontos, deve almejar a consolidação de uma cidadania que anseie a participação na gestão de assuntos da sociedade, de forma a modificar de fato as relações e o ambiente, e que não represente apenas mais um mecanismo de controle e normatização. O cidadão deve empoderar-se do espaço público e integrar-se à sociedade, com plena consciência do que a coletividade representa.

Para Layrargues (2000), a autonomia, emancipação, participação, cidadania e a justiça social são os meios a serem edificados em nosso cotidiano e não apenas metas a serem atingidas. Nesse caminho, vamos compreendendo que para se fazer uma Educação Ambiental Crítica é necessário associá-la a uma cidadania também crítica, reconhecendo que dentro da sociedade não há somente convergência, mas conflitos de interesses e que as classes hegemônicas impõem continuamente sua visão de cidadania.

\section{A experiência estética a favor de uma Educação Crítica}

Acreditamos que a experiência estética é uma alternativa para escapar do atual sistema de valores, pois educa para o sensível e permite que o indivíduo contemple a realidade de forma concreta, livre dos conceitos construídos pelo mercado. Afinal, "a maneira como vemos as coisas é afetada pelo que sabemos ou acreditamos" (BERGER, 1999, p.10). Sob a mesma perspectiva, Marin e Oliveira (2005, p. 14), afirmam que "quem vivencia o fenômeno da experiência estética tem diante de si um mundo muito mais amplo e flexível que aquele desenhado pelas sociedades de consumo". Desse modo, a experiência estética, além de possibilitar uma melhor compreensão da realidade, permite o vislumbre de alternativas de convívio e interação com o meio, pautadas nas reais necessidades da sociedade. Salientando que a estética a ser construída e defendida está pautada na criticidade e, sendo assim, se opõe a uma estética hegemônica.

Para Santos (1992), a condução da técnica pelos grandes atores da economia e da política, leva a uma escravização do ser humano, onde as ações dos soberanos podem ter objetivo, mas não têm sentido. O autor ressalta que não só a natureza se apresenta degradada, mas também a moral, pois a valorização de objetivos econômicos acima dos sociais se apresenta na carência de um sentido comum. Barchi (2009) apresenta como alternativa a esses sistemas, entre outras questões, uma educação ambiental onde os indivíduos constroem-se a si mesmos, em diálogo sempre ativo com os outros, ou seja, sempre mutáveis e nunca terminantes. Para Duarte (2000), uma educação para a sensibilidade, frente ao presente ensino pautado na racionalidade instrumental, fica próxima a uma revolução nas atuais condições do ensino, mas que carecem de barreiras a serem atravessadas. Aqui, não temos a intenção de estabelecer uma metodologia rígida para despertar a sensibilidade nos alunos, apenas propor uma relação entre o despertar da sensibilidade e da criticidade para uma educação ambiental efetiva. Guimarães (2004) entende que as ações pedagógicas de caráter crítico como um todo, dentre outras contribuições: 
Exercita a emoção como forma de desconstrução de uma cultura individualista extremamente calcada na razão e a construção do sentimento de pertencimento ao coletivo, ao conjunto, ao todo, representado pela comunidade e pela natureza. Incentiva a coragem da renúncia ao que está estabelecido, ao que nos dá segurança, e a ousadia para inovar (p. 32).

Assim, enxergando a relação e a importância entre a experiência estética e a Educação Ambiental, optamos por abordar as possibilidades que a arte participativa (neste trabalho, fotografia, pintura e desenho, especificamente) apresenta para contribuir com experiências sensíveis diversas, bem como para o estímulo à reflexão. Do mesmo modo, consideramos a importância da criatividade e da imaginação para o vislumbre de novas possibilidades de mundo, elementos diretamente relacionados com a prática artística.

A arte, expressão da inteligência e sensibilidade do humano, pode proporcionar diversas experiências sensoriais e cognitivas, faz fronteira com a imaginação, promove 0 encontro entre diferentes realidades e culturas, incita a percepção de questões referentes ao domínio dos sentimentos, considera até o que é impreciso, o não-científico. Porém, podendo, por conta de suas caraterísticas mais abrangentes, contribuir com a educação, com a ciência. A arte pode até ajudar a reformar a ciência. Para Marin e Oliveira (2005), a arte possui a competência de fundar novos valores, abrindo novas perspectivas sustentadas pela liberdade. Perspectivas estas que podem levar o ser humano a se libertar de valores que the são incutidos como necessidades. Nessa perspectiva, Morin (2007, p. 53) afirma que "o homem se aproxima da crítica ao mecânico e ao instrumental pela prática das artes, da poesia, da música, do teatro, para mencionar apenas esses modos de expressão, fontes epífanas do belo e do bem".

Para Duarte (2000), a experiência estética (a qual o autor se refere como educação do sensível) não deve significar uma mostra de arte, com exibições e promoções de obras consagradas, mas deve primeiramente se voltar para o cotidiano, para o ambiente que rodeia o educando, de modo a provocar sensibilizações com estímulos rotineiros. Contudo, a arte por si só não educa para o sensível, deve ser um meio para isso e deve ser trabalhada juntamente com reflexões sobre a própria manifestação artística a que o aluno está sendo apresentado. Afinal, as manifestações artísticas são produções humanas, portanto não são neutras. Em muitos momentos a arte pode ser conservadora e retrógrada, pois de acordo com Berger (1999), a arte tende a servir aos interesses ideológicos das classes dominantes, isso em qualquer período histórico. Apesar disso, existe a arte que nasce da inquietação. Litvak (1985, p.69), ao abordar as contribuições dos anarquistas para a arte espanhola, discorre sobre uma arte que seja criação da classe trabalhadora e que destrua "o status da obra de arte enquanto privilégio das classes abastadas e enquanto produto exclusivo de artistas profissionais". Guattari ressalta essa questão ao afirmar que:

É nas trincheiras da arte que se encontram núcleos de resistência dos mais consequentes ao rolo compressor da subjetividade capitalística, a da unidimensionalidade, do equivaler generalizado, da segregação, da surdez para a verdadeira alteridade (GUATTARI, 2012, p. 105).

E quando se trata da arte contestadora, "como ação de quem pensa diferente do que se instituiu no regime de verdades legitimado e instituído socialmente (pela academia, pelos partidos políticos, pelas corporações econômicas, pela moralidade cristã, pela família)" 
(ANDRÉ, 2011, p. 434), também levamos em conta a sensibilidade que provoca. E vale destacar que a sensibilidade aliada à criticidade tem o poder de gerar grandes questionamentos e mudanças. Duarte (2000, p. 186) afirma que quanto maior a sensibilidade, "menor é a anestesia perante a profusão de maravilhas que este mundo nos permite usufruir e saborear." A EA-Crítica deve contribuir para uma mudança de valores e atitudes, de modo a guiar para uma subjetividade "orientada por sensibilidades solidárias com o meio social e ambiental" (CARVALHO, 2004, p. 19), que permita a formação de indivíduos capazes de analisar e agir frente a uma determinada questão socioambiental, tendo a empatia e a alteridade como orientação. Desse modo, é indispensável, em EA, trabalhar a sensibilidade, com o desenvolvimento de valores intrínsecos ao ser humano, e a arte pode se apresentar como recurso para esse fim.

\section{O encontro entre a Educação Ambiental Crítica e a Arte Participativa: nossa trajetória metodológica}

A investigação deste artigo possui abordagem qualitativa, pois os processos a serem estudados são complexos, envolvendo valores, hábitos e opiniões. Tozoni-Reis e TozoniReis (2004) ressaltam que, como a Educação Ambiental refere-se a fenômenos históricos, culturais, humanos e sociais, é necessária uma metodologia que corresponda a essa complexidade, como uma pesquisa qualitativa, que não abre mão do método, mas possui uma flexibilidade necessária às investigações sociais.

Optamos por uma pesquisa participante pela estruturação de um projeto elaborado com base na participação ativa dos envolvidos e na problematização de questões locais ao grupo trabalhado, assim como optamos também pela construção coletiva de uma proposta que busque soluções para essas questões. Utilizamos como principal referencial teórico para a nossa metodologia de pesquisa participante, a obra de Brandão (1999). E também porque essa proposta metodológica convergiria, inclusive, com o que vamos chamando de "arte participativa".

Convergimos nossa pesquisa participante ao modelo proposto por Le Boterf (1999), fazendo algumas adaptações devido às particularidades de uma investigação realizada em uma instituição escolar. Assim, iniciamos com a montagem institucional e metodológica da pesquisa, correspondendo ao processo de seleção do grupo participante e à comunicação do procedimento à instituição de ensino, bem como a elaboração e organização das atividades iniciais a serem desenvolvidas com o grupo. Em seguida, partimos para o estudo preliminar e provisório do local e do grupo envolvido. Esta fase corresponde ao estudo histórico da região e às condições socioambientais atuais. Esta segunda etapa entremeou as atividades realizadas com os alunos e os resultados eram constantemente debatidos com as turmas. A terceira fase da pesquisa corresponde à análise crítica dos problemas que o grupo considera prioritários. Neste momento, debatemos as fotografias tiradas pelos alunos, que foram orientados a escolher e fotografar um problema de cunho socioambiental da região em que vivem ou frequentam. A quarta fase do método, é direcionada para a programação e aplicação de um plano de ação que contribua para a solução dos problemas encontrados. Este plano de ação, em nosso caso, foi expresso através dos desenhos elaborados pelos alunos, representando as propostas ou críticas aos 
problemas apresentados. O feedback dos resultados obtidos ao longo do processo foi constante e concomitante durante o percurso metodológico.

Foram utilizados dois instrumentos de coleta de dados: observação e imagens produzidas pelos alunos (fotografias e desenhos). Para Freire (1981), a realidade concreta vai além de dados materiais e fatos, pois devemos considerar também, a percepção que a população envolvida possui desses dados e fatos, sendo a realidade concreta a relação dialética entre objetividade e subjetividade. Assim, a observação permeou todas as aulas e teve como objetivo captar relatos e interações com os participantes, de modo a registrar aspectos dos discursos dos estudantes e complementar os dados referentes às fotografias e aos desenhos. As fotografias e os desenhos representaram a capacidade de análise e julgamento dos estudantes frente às questões trabalhadas em sala de aula.

A pesquisa foi realizada no Colégio Estadual Prefeito Luiz Guimarães, localizado no bairro Nossa Senhora de Fátima, em Queimados. As atividades foram realizadas com duas turmas de terceiro ano do ensino médio, do terceiro turno (noite) e compostas por um grupo relativamente homogêneo quanto à faixa etária e moradia. Possuem entre 17 e 24 anos de idade e residem no município de Queimados, em bairros diversificados.

As atividades com os alunos foram aplicadas dentro do tempo de aula, referente à disciplina de Biologia (dois encontros semanais), com a temática central "humanidade e ambiente". Elaboradas pautadas em uma EA-Crítica, buscamos evidenciar as questões complexas associadas à problemática ambiental de forma a permitir que o aluno desconstrua a visão fragmentada entre natureza e sociedade, e compreenda a incompatibilidade entre justiça socioambiental e capitalismo. As atividades trazem também uma abordagem dos ecossistemas de forma a facilitar a compreensão da conectividade da natureza, que não reconhece fronteiras humanas.

Abarcando o campo da sensibilidade, atividades voltadas para a análise de imagens foram propostas, de modo que os alunos consigam perceber os próprios sentimentos ao receber um estímulo visual. É um exercício importante, pois somos expostos em nossos cotidianos a uma série de imagens que trazem significações, mas que anestesiam nossos sentidos, fazendo com que passemos a observar o mundo a nossa volta de forma irreflexiva. A reflexão acerca das imagens e dos sentimentos possibilitaram uma discussão sobre a estética que nos tem sido imposta e suas consequências para nossas relações interpessoais e nosso ambiente.

Assim, após trabalhar os aspectos cognitivos (biológicos e sociais) e os sensíveis, foi dada continuidade à participação ativa dos estudantes com a responsabilidade conjunta em elaborar desenhos inspirados no local onde vivem e construídos através do olhar crítico e sensível. Guimarães (2004, p. 29) afirma que para que uma educação ambiental crítica possua uma ação diferenciada: "é necessária a práxis, em que a reflexão subsidie uma prática criativa e essa prática dê elementos para uma reflexão e construção de uma nova compreensão de mundo", e que esse é um processo vivenciado na relação com o coletivo.

Apesar de inicialmente apresentarem um estranhamento à prática de ensino diferenciada, os alunos demonstraram grande aceitação aos temas abordados e tiveram participação ativa ao longo das aulas. Os debates contribuíram expressivamente para o caminhar deste trabalho, assim como forneceram importantes informações a respeito dos locais que os estudantes frequentam e da forma como enxergam a própria realidade.

Após as atividades, demos início à análise dos dados oriundos das fotografias, desenhos e da observação realizada ao longo dos encontros. 


\section{O que encontramos e construímos, afinal?}

Ao longo do processo metodológico foram registrados dados referentes aos relatos e interações advindos dos encontros, inclusive as fotografias e os desenhos elaborados pelos alunos. Para a análise dos dados referentes à pesquisa participante que foi desenvolvida, fizemos uso de livre interpretação, buscando, ao analisar as representações e a imaginação dos educandos sobre o ambiente que os cerca, conhecer seus posicionamentos como sujeitos históricos, assim como suas relações com o espaço.

A partir da relação entre ideologia, historicidade e experiências simbólicas, devemos considerar a produção de diferentes sentidos e buscar a responsabilidade desses sentidos para a concepção ambiental dos alunos. Quando nos referimos aos dados resultantes deste trabalho, estamos considerando elementos como imagens, textos, interpretações e até mesmo o silêncio, basta que produza sentido para interpretação. Ao longo da análise dos dados, buscamos uma aproximação que considerou aspectos intuitivos, de apreensão básica, com uma compreensão que foi sendo construída com o auxílio dos alunos e, por isso, apreciando questões que dialogam com o senso comum.

Após trabalhar os aspectos cognitivos, promovemos uma provocação através de imagens (pinturas e fotografias). As imagens foram exibidas em PowerPoint e contaram com obras de artistas distintos (Picasso, Munch, Klimt, Frida Kahlo, Portinari e Tarsila do Amaral). Buscamos com essa atividade, além de despertar o olhar do aluno para uma experiência estética, diagnosticar a capacidade perceptiva dos mesmos com estímulos externos distintos, aos próprios sentimentos.

Findada a exibição de quadros, os alunos foram questionados: "Por que conseguimos definir o que sentimos ao observar imagens construídas por pintores, mas não temos esse hábito ao observar o mundo que nos cerca?" Alguns alunos citaram o costume e o hábito como barreira para a observação mais atenta dos locais que frequentam, outros já se referiram aos quadros, alegando que possuem elementos que permitem um despertar maior da sensibilidade. Ao fim do debate, prosseguimos com a exibição de outras imagens, desta vez buscando um esquema de "antes e depois" e mesclando obras de arte e fotografias. Os alunos só foram informados da ligação entre as imagens após a atividade. Os ambientes escolhidos para a abordagem ambiental foram: baía de Guanabara, rio Tietê e Serra do Espinhaço, em Minas Gerais. Esses locais foram escolhidos devido ao grau de degradação que atingiram, assim como por existirem obras artísticas que representam esses ambientes ainda preservados, como "Baía de Guanabara vista da llha das Cobras" de FélixÉmile Taunay (1828), "Rio Tietê" de Cândido Portinari (1935) e "Serra" de Mário Zavagli (2013/2014).

Com essa atividade, podemos perceber que os alunos apresentam maior facilidade em analisar as obras de arte que as fotografias, assim como muitas vezes se atêm mais a figuras humanas que a paisagens.

Após a provocação sensível dos alunos, partimos para a próxima etapa de nossa metodologia, onde os estudantes foram convidados a levar um novo olhar para a realidade, com o exercício de contemplar o ambiente que os cerca. Para que o indivíduo produza conhecimento sobre a sua realidade, é fundamental a participação efetiva do sujeito, de forma que a observação do próprio ambiente e dos problemas que o afetam (seja de forma direta ou indireta) criem conhecimentos e resulte em ações (JANKE; TOZONI-REIS, 2008). Assim, foram orientados a identificar e registrar com fotografias, amostras de conflitos socioambientais nos espaços que frequentam ou transitam. 
Para Rêgo (2006), a fotografia, como linguagem, pode carregar particularidades que dependerão do fotógrafo, que criativamente escolhe luz, ângulo, foco, enquadramento, enfim, características que permitem que seja caracterizada como uma dimensão artística. A autora ressalta que apesar de toda técnica envolvida da prática da fotografia digital, a emoção ainda permeia o ato do fotógrafo, que se motiva e se sensibiliza por uma dada imagem, "de um aspecto do real no seu cotidiano contaminado pelo olhar sensível de sua imaginação" (p. 47). Ao fazerem os registros das questões socioambientais, os alunos foram levados a uma observação mais cuidadosa de seus ambientes de convívio, exigindo maior sensibilidade quanto à escolha do registro e criticidade para identificar e analisar as questões socioambientais.

As fotografias são acompanhadas por desenhos compostos pelos alunos, representando críticas ou soluções propostas pelos mesmos, como uma releitura da realidade. Para Moreira (1984), o desenho funciona como linguagem, sendo uma possibilidade de projeção de ideias e sentimentos. A autora define o ato de desenhar como a junção entre pensamento e sentimento. $O$ desenho ainda é capaz de dar concretude ao processo criativo do aluno, processo este que, segundo Ostrower (1993) é inerente e necessário ao homem, e diretamente ligado à capacidade de compreensão. Desta forma, os alunos, através da sensibilidade e compreensão da realidade observada, fizeram uma releitura das fotografias de forma criativa, imprimindo identidade aos desenhos elaborados.

As fotografias foram feitas de forma individual pelos estudantes, mas a análise das imagens, as propostas para as questões apresentadas e as transposições das figuras constituíram atividades coletivas, sempre considerando os relatos e opiniões dos estudantes ao longo do processo. Por envolver fotografia e desenho, a atividade desenvolvida é uma possibilidade de alternar registro e produção, explorando a possibilidade de exploração e criação de sensibilidades e também a produção de imagens-registro (AMORIM e GONÇALVES, 2015).

Fizemos uma análise individual e minuciosa de cada fotografia e desenho produzidos pelos alunos, de forma a identificar os aspectos ocultos dessa produção, assim como avaliálos quanto à capacidade de associação da realidade à Educação Ambiental Crítica. Assim, findada a análise das imagens e considerando os dados obtidos na atividade anterior, podemos notar que, apesar dos alunos terem dado maior foco em figuras humanas na exibição das obras de arte, pouquíssimos registros apresentaram este elemento.

Analisamos os temas registrados em cada fotografia, de modo a determinar os aspectos locais que mais afetaram a sensibilidade dos alunos. Observamos que, em vinte e um (21) registros, o lixo teve o maior número de referências, com um total de dez (10). A subutilização de espaços contou com sete (7) referências, enquanto a poluição hídrica, o saneamento deficiente e a ausência de pavimentação tiveram cinco (5) registros cada. A exploração de recursos naturais apresentou apenas uma (1) referência. Uma fotografia pode fazer referência a mais de um tema, sendo comum a associação, principalmente, do lixo com a subutilização de espaços, e da poluição hídrica com saneamento deficiente.

De um total de vinte e um (21) desenhos elaborados pelos alunos, apenas seis (6) fizeram referência à representação humana e, das seis (6) referências, em três (3) a figura humana é utilizada para destacar aspectos negativos. $O$ pensamento impregnado atualmente, em que não existe a possibilidade de convivência harmônica entre ser humano e natureza, onde devemos optar entre a preservação e a urbanização ainda é muito forte e demonstra a dificuldade em vislumbrar novos modelos de sociedade. Além disso, as 
soluções propostas demonstram que, caso existisse a necessidade de escolha por parte desses alunos, escolheriam a urbanização em detrimento da manutenção dos aspectos naturais, visto a quantidade de propostas higienistas aos problemas observados. Nas fotografias, a criminalidade estava oculta, mas não foram poucos os alunos a afirmarem terem feito o registro fotográfico às escondidas, com receio de represália por parte do movimento associado ao crime organizado no local. Apesar dos relatos, não houve referência direta à questão da violência nas transposições.

Os desenhos deveriam representar a capacidade crítica frente aos problemas apresentados nas fotografias. Conforme citado anteriormente, houve pouca referência à figura humana e a urbanização prevaleceu nas propostas, comparado ao resgate de aspectos ambientais. Claramente devemos considerar a provável dificuldade em analisar profundamente as questões ambientais quando a população carece de recursos básicos e se preocupa em preservar a vida em um cenário constante de violência. A proposta de limpeza teve um total de dez (10) referências nos desenhos, seguida por urbanização e áreas de lazer, ambas com oito (8) referências. Reciclagem e crítica social tiveram três (3) referências e a proposta de oferta de serviços públicos tiveram duas (2) referências.

Considerando que as fotografias e desenhos apresentam-se em conjunto, se ilustrássemos todos os registros no presente trabalho, precisaríamos acrescentar um total de vinte e uma (21) imagens. Em vista da limitação espacial, optamos por disponibilizar um exemplo de cada referência feita nos desenhos, acompanhada de seu registro fotográfico. Nesse caso, proposta de limpeza (Figura 1), áreas de lazer (Figura 2), reciclagem (Figura 3), urbanização (Figura 4), crítica social (Figura 5) e oferta de serviços públicos (Figura 6).

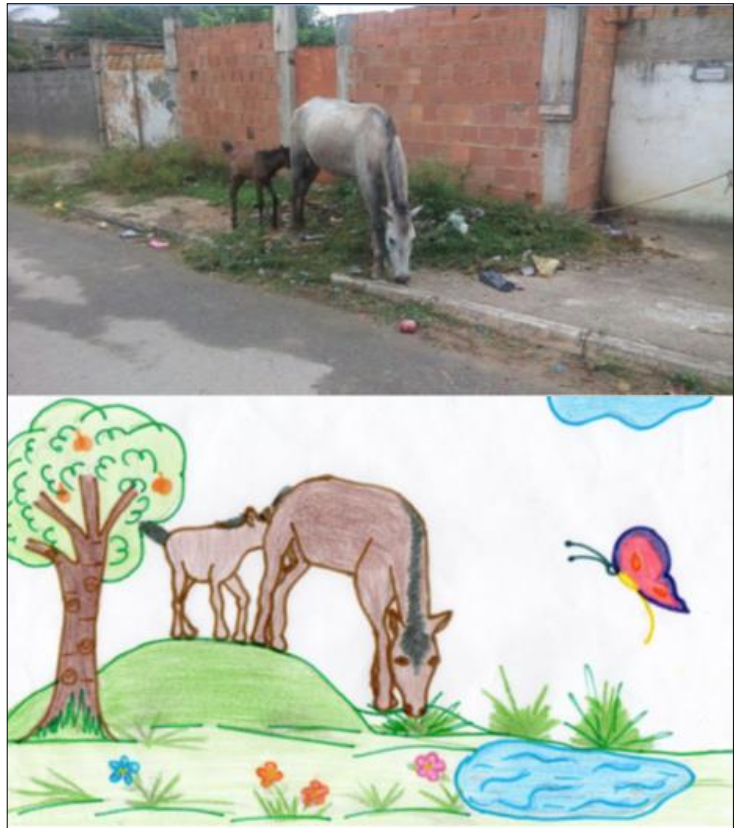

Figura 1: Cavalos no campo.

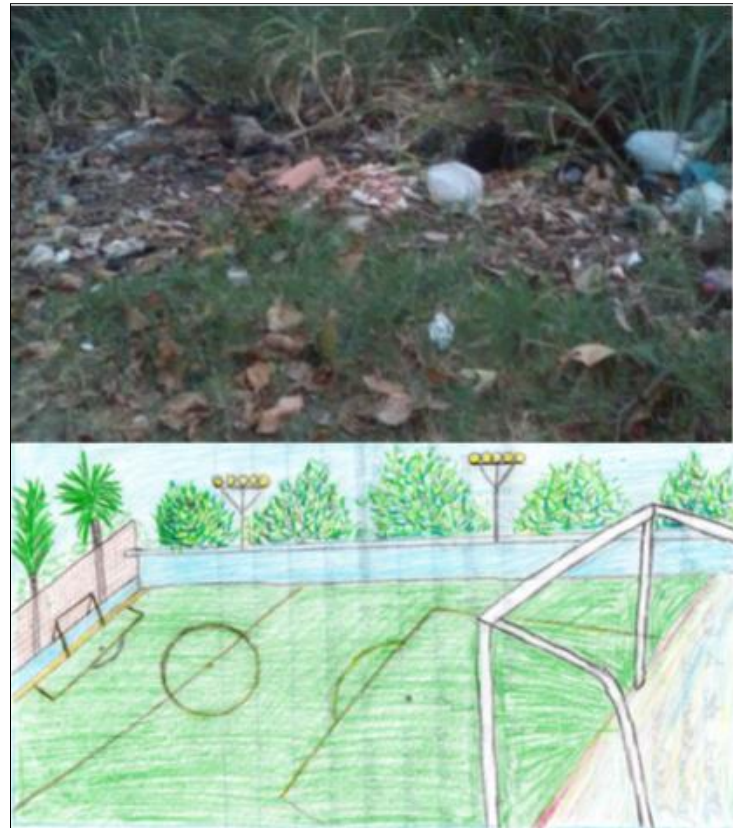

Figura 2: Quadra de futebol 


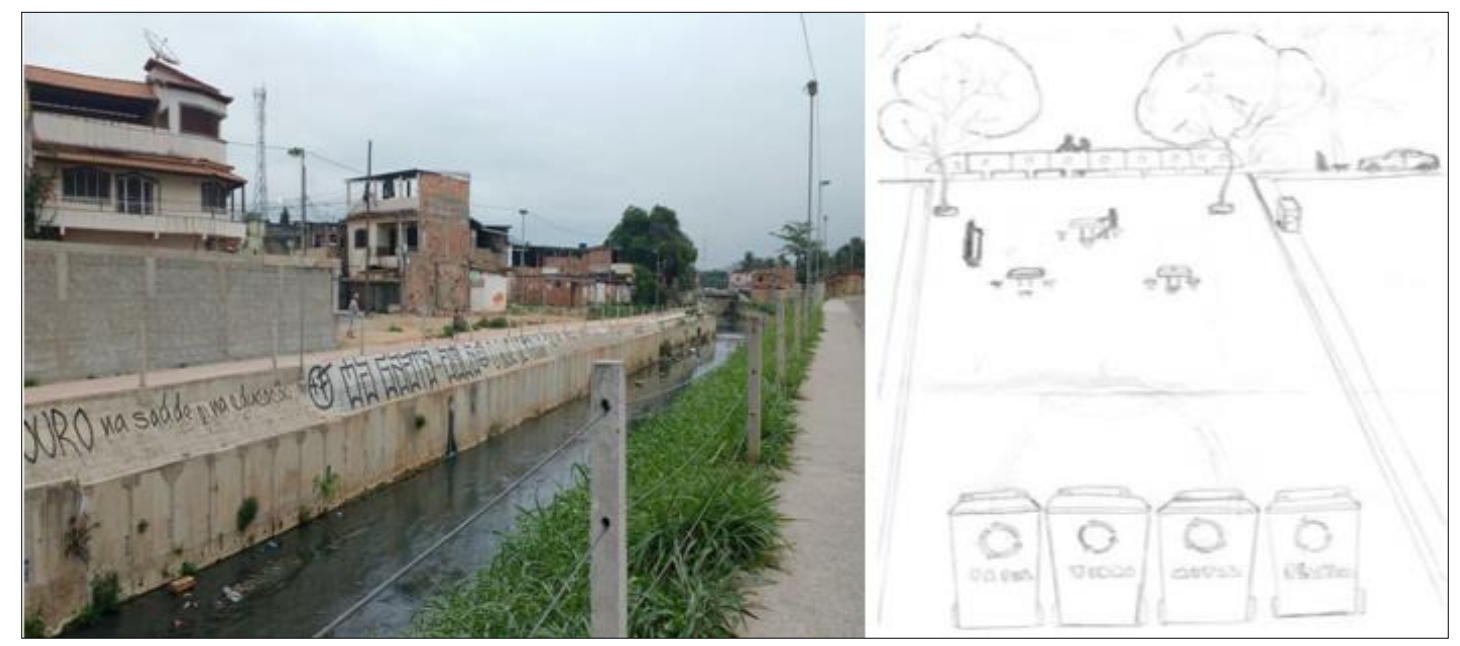

Figura 3: Do rio à praça.

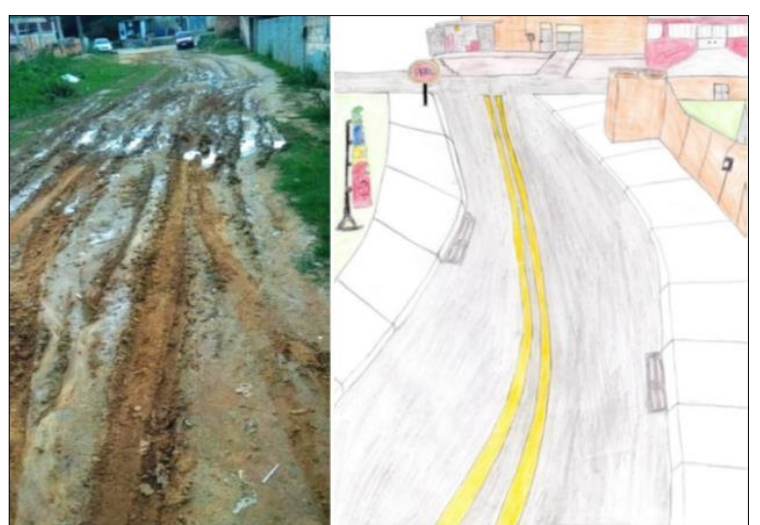

Figura 4: Urbanização, limpeza e conforto.

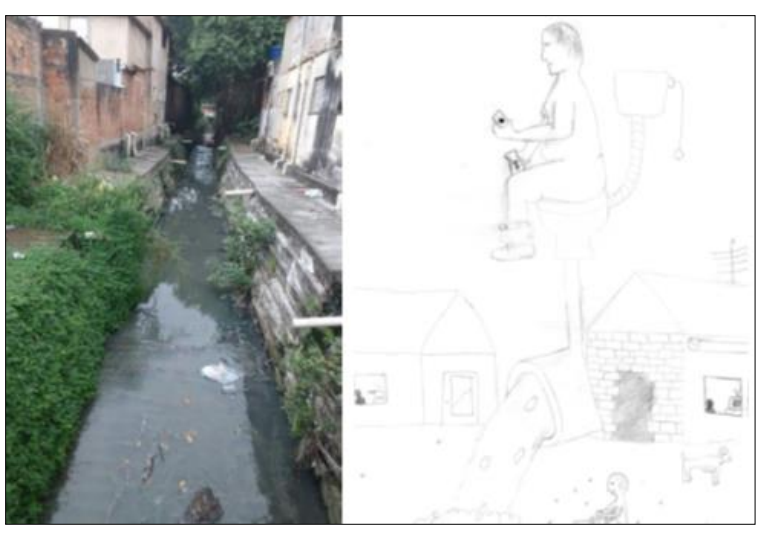

Figura 5: Rejeitos da desigualdade

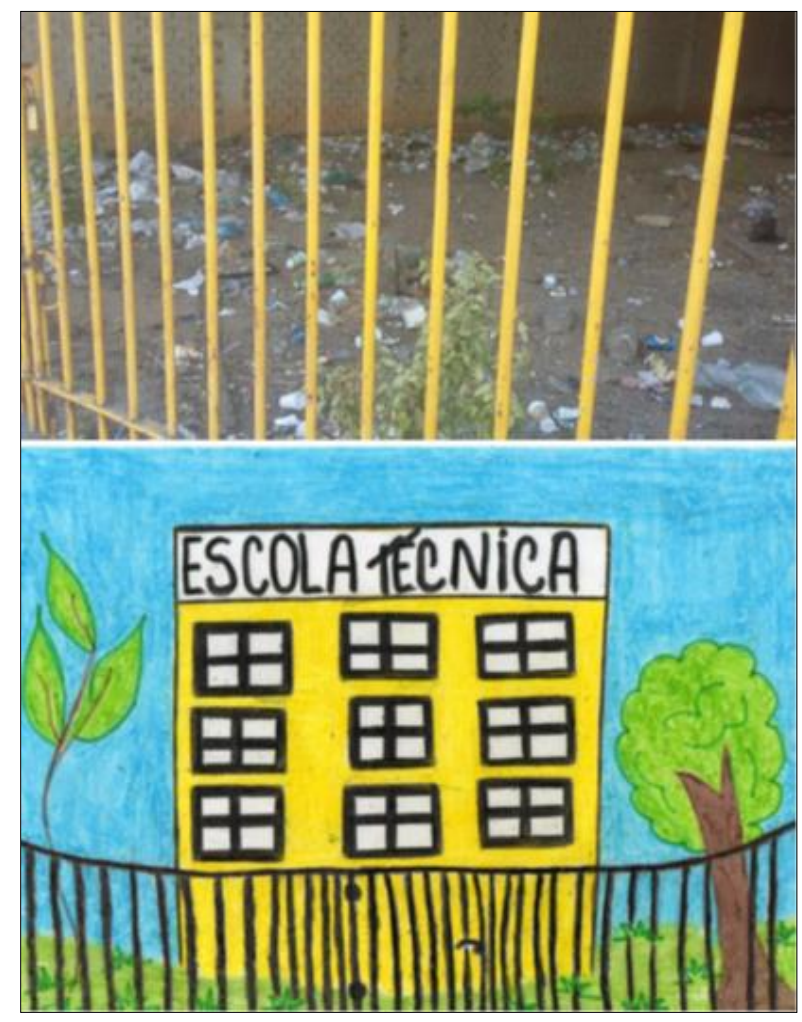

Figura 6. Escola técnica. 
Após a análise das produções dos alunos, percebemos que nosso objetivo foi parcialmente atingido, visto a quantidade de referências a propostas voltadas para uma EA Comportamentalista e para processos de urbanização convencionais. Isso nos levou a uma reflexão a respeito das etapas ao longo do processo. É fato que o tempo foi curto para aprofundar os debates. Além disso, a infrequência no terceiro turno é alta, o que acabou por ferir a continuidade das atividades para muitos alunos, prejudicando a assimilação do conteúdo trabalhado. É possível que atingíssemos uma maior qualidade na produção dos desenhos, caso as atividades tivessem ocorrido de forma voluntária, com reduzida participação. Porém, como argumenta Morin (2007, p. 50), "isolar o objeto observado do meio circundante comporá certas vantagens, mas também um inconveniente maior: o de fazer abstração daquilo que não está separado da realidade". Desta forma, considerando que o objetivo era exatamente reconhecer as possibilidades e limitações de promover um trabalho com Educação Ambiental Crítica e artes, dentro da realidade da escola pública, continuamos apoiando a proposta de manter uma coletividade.

Além das questões acima assinaladas, é essencial considerar a força dos discursos adotados em diversas esferas (inclusive nas escolas) a respeito da questão ambiental. Conforme anteriormente citado por Simões (2006), os grupos políticos que atuam na cidade de Queimados ficam em grande parte restritos a reivindicações por melhorias nas condições de vida dos moradores, possuindo ínfima abordagem em mudanças econômicas, políticas e sociais de caráter estrutural. Essa característica atravessa as diferentes camadas da população e constrói significados. Brandão (2004) afirma que o discurso é capaz de efetivar a materialidade ideológica e que a ideologia não explicita as diferenças e contradições sociais, o que faz com que o discurso ideológico apresente "lacunas" e "silêncios" que promovem a preservação do sistema. Para Brandão (2004), o discurso ainda pode manifestar subjetividades diversas, o que acaba por retirar o mesmo do papel de gerador de significações. Freire (1996) destaca que uma característica do poder ideológico hegemônico é o direcionamento aos dominados da responsabilidade pela situação desvantajosa em que se encontram. Para Freire "a ideologia tem que ver diretamente com a ocultação da verdade dos fatos, com o uso da linguagem para penumbrar ou opacizar a realidade ao mesmo tempo em que nos torna 'míopes'" (p. 79). O autor adverte para a importância de o educador estar atento para a forma como a ideologia dominante imprime uma suposta neutralidade da educação. Partir desta proposta reacionária de neutralidade faz com que os alunos sejam orientados para práticas despolitizadas, ignorando que a própria existência não é neutra (FREIRE, 1996).

Chauí (1980), ao fazer uma caracterização de ideologia, segundo os preceitos marxistas, afirma que a ideologia é um instrumento de dominação de classes, pois a classe dominante faz com que suas ideias sejam as ideias de todos. A ideologia se faz necessária para a dominação de classe, pois inverte a realidade e torna imperceptíveis as contradições da sociedade. Assim, o discurso ideológico que ainda prevalece em diversas camadas da sociedade, é de incompatibilidade entre progresso e preservação, onde ser humano e natureza não podem coexistir em um mesmo espaço e, nosso papel se restringe a reciclar, economizar água, dentre outras ações individuais. O único modelo de progresso que a sociedade assimila, é pautado no desenvolvimentismo, no crescimento econômico e, de fato, esse modelo é incompatível com a preservação ambiental e com a justiça social.

Em vista da dificuldade dos estudantes em vislumbrar um modelo de sociedade onde prevaleça o equilíbrio entre natureza e ser humano, consideramos essencial o estímulo à 
criatividade, de modo a expandir as mentes engessadas pelo poder ideológico. Dessa forma, "é preciso lembrar o homem de seu poder criativo, inventor de si, para que se veja menos como um a mais do que como único. Ir na contramão do ideal econômico que infertiliza a mente humana e suas criações" (AMORIM e CASTANHO, 2008, p. 5). Sob essa perspectiva, devemos refletir sobre as responsabilidades de uma educação que se propõe crítica em encorajar a capacidade criativa, para que os indivíduos possam conjecturar uma sociedade radicalmente diferente, liberta da lógica do mercado e pautada no respeito a todas as formas de vida.

\section{Considerações finais}

Avaliando as atividades e produções construídas ao longo deste trabalho, consideramos que levar os alunos a uma observação crítica de seu ambiente, sob uma perspectiva social e histórica, promoveu um aprendizado com potencial de transformação, deslocando conteúdos que normalmente são abordados de forma generalista e descontextualizada, para a realidade dos educandos. Sabemos que a educação escolar por si só não é suficiente para que possamos atingir mudanças radicais efetivas nos parâmetros das discussões aqui levantadas, assim como sabemos ser difícil para os educadores transformarem a realidade tão dura deste país, porém podem apontar que alguma transformação é possível (FREIRE, 1996). Considerando a força da manipulação ideológica pela mídia, produtora de subjetividades que promovem a manutenção do sistema hegemônico, deixamos escrito aqui a tarefa difícil de desconstruir conceitos que constituem os interesses dos grupos dominantes da sociedade atual. Destarte, evidenciar as contradições da nossa sociedade e sua influência nas relações com o meio, ao menos orientará o olhar do indivíduo para perceber as tentativas de encobrir as reais causas da desigualdade e da degradação ambiental, bem como as relações entre elas.

Vale ressaltar que as atividades realizadas geraram debates em que os estudantes explanaram diferentes opiniões sobre o ambiente, fortalecendo um processo dialógico. As atividades com artes demonstraram competência em prover a união entre os alunos, com o compartilhamento de materiais e orientação técnica pelos indivíduos com maior habilidade artística. Além disso, os estudantes foram muito receptivos à possibilidade de um método de avaliação diferenciado, onde se tornaram sujeitos ativos na busca por uma solução pautada no conteúdo trabalhado em sala de aula, fazendo uso de uma atividade lúdica e contrariando a lógica avaliativa puramente teórica, normalmente adotada nas instituições de ensino.

Os desenhos possibilitaram a análise da capacidade de assimilação do conteúdo, da imaginação dos alunos quanto à questão ambiental e das necessidades e anseios da população local quanto às questões estruturais urbanas. Atingimos uma produção diversificada, porém tivemos uma grande incidência de propostas voltadas para a urbanização, com aspectos naturais e humanos muitas vezes ausentes. Assim, consideramos que frente ao descaso socioambiental histórico de toda uma região, os desejos e necessidades de um ambiente digno, se sobrepõem à preocupação com a natureza. Isso expõe ainda, a dificuldade dos estudantes em vislumbrar uma estética urbana diferente da estética hegemônica.

Ainda que os desenhos produzidos tenham mantido limites e contradições, conforme apontam uma Educação Ambiental Crítica, proporcionaram um material de grande valor 
para análise da pesquisa em si, mas também à formação dos alunos. A abordagem de aspectos socioambientais locais, fazendo uso da arte para sensibilizar e promover uma nova forma de expressão, assim como a participação ativa dos estudantes ao longo do processo educativo, possibilitou um aprendizado crítico, em que os alunos passaram a enxergar o ambiente em que vivem de forma contextualizada. As fotografias e os desenhos, criação integral desses estudantes da rede pública estadual não somente permitiram uma leitura crítica da realidade, como também geraram um novo olhar à prática educativa, pois os alunos assumiram postura ativa e passaram por um processo de empoderamento da construção do conhecimento.

Consideramos que os maiores desafios para atingir de forma plena os objetivos traçados por uma proposta educativa pautada na Educação Ambiental Crítica, estejam nas limitações institucionais, na baixa integração entre as disciplinas e, principalmente, no desafio que é lutar contra um processo massivo de doutrinação que busca encobrir o entendimento da natureza holística das relações ambientais e que reforça a dissociação entre natureza e sociedade. O desafio é esse, lutar contra o modo como se constroem falsas necessidades, buscando a libertação dos conceitos construídos pelo mercado. Essa luta é dura, visto que somos bombardeados com imagens e julgamentos voltados para este fim desde a mais tenra idade, antes mesmo do primeiro contato com escola. Assim, talvez a luta contra o processo alienatório seja desigual, mas devemos traçar um objetivo (ainda que distante) e considerar uma vitória de cada vez. Mas, a melhor conclusão a se obter e registrar é que essa experiência de educação e arte precisa assumir a disputa estética existente, portanto para ela ser, de fato, transformadora e emancipadora, deve optar pelo confronto e não pela "paz" que vem da alienação.

\section{Referências}

ACSELRAD, H. Meio Ambiente e Justiça: estratégias argumentativas e ação coletiva. Justiça ambiental e cidadania. Rio de Janeiro: Relume Dumará, p. 23-40, 2004.

AMORIM, V. M.; CASTANHO, M. E. Da dimensão estética da aula ou do lugar da beleza na educação. Reflexão e Ação, v. 15, n. 1, p. 158-173, 2008.

AMORIM, A. C. R.; GONÇALVES, M. L. C. M. R. Naturezas artificiais e a diferença paradoxal entre ciências e culturas. Interacções, v. 10, n. 31, 2015.

ANDRÉ, C. Arte, biopolítica e resistência. Revista Brasileira de Estudos da Presença, Porto Alegre, v. 1, n. 2, p. 426-442, 2011.

BARCHI, R. Contribuições "inversas", "perversas" e menores às educações ambientais. Instituto Politécnico de Santarém, Escola Superior de Educação. Revista Interacções, n011, p.174-192, 2009.

BERGER, J. Modos de ver. Tradução de Lúcia Olinto. - Rio de Janeiro. Rocco, 1999.

BOMFIM, A. M.; PICCOLO, F. D. Educação ambiental crítica: a questão ambiental entre os conceitos de cultura e trabalho. Revista Eletrônica Mestrado Educação Ambiental. ISSN 15171256, v. 27, 2011.

BRANDÃO, C. R. Pesquisa participante. 2ª ed. São Paulo: Brasiliense, 1981.

BRANDÃO, C. R. Repensando a pesquisa participante. São Paulo: Brasiliense, 1999. 
BRANDÃO, H. H. N. Introdução à análise do discurso. $2^{a}$ ed. rev. Campinas, SP: UNICAMP, 2004.

CARVALHO, I. C. de M. Educação ambiental crítica: nomes e endereçamentos da educação. Identidades da educação ambiental brasileira. Brasília: Ministério do Meio Ambiente (2004): $13-24$

CHAUÍ, M. de S. O que é ideologia. São Paulo: Brasiliense, 1980.

DUARTE, J. R. J. F. O sentido dos sentidos: a educação (do) sensível. 2000. UNICAMP: Programa de Pós-Graduação em Educação, Tese (doutorado). 234p.

FREIRE, P. Criando métodos de pesquisa alternativa: aprendendo a fazê-la melhor através da ação. In: BRANDÃO, C. R. Pesquisa participante. São Paulo: Brasiliense (2ª edição), 1981. 211 p. p. 34-41.

FREIRE, P. Pedagogia da autonomia: saberes necessários à prática educativa. São Paulo: Paz e Terra, 1996.

GUATTARI, F. As três ecologias. Tradução Maria Cristina F. Bittencourt. Campinas: Papirus, 1990.

GUATTARI, F. Caosmose: um novo paradigma estético; tradução de Ana Lúcia de Oliveira e Lúcia Cláudia Leão. São Paulo: Editora 34, 2012 (2ª edição). 192 p.

GUIMARÃES, M. Educação ambiental crítica. Identidades da educação ambiental brasileira. Brasília: Ministério do Meio Ambiente, p. 25-34, 2004.

JANKE, N.; TOZONI-REIS, M. F. D. C. Produção coletiva de conhecimentos sobre qualidade de vida: por uma Educação Ambiental participativa e emancipatória. Ciência \& Educação, v. 14, n. 1, p. 147-157, 2008.

LAYRARGUES, P. P. Educação para a gestão ambiental: a cidadania no enfrentamento político dos conflitos socioambientais. Sociedade e meio ambiente: a educação ambiental em debate. São Paulo: Cortez, p. 87-155, 2000.

LE BOTERF, G. Pesquisa participante: Propostas e reflexões metodológicas. In: BRANDÃO, C. R. Repensando a pesquisa participante. São Paulo: Brasiliense, 1999. 252 p. p. 51-81.

LITVAK, L. Arte anarquista espanhola de fins do século XIX. Tradução Antônio Arnoni Prado. Coleção Remate de Males. Número 5, p. 69-85, 1985.

MARIN, A.; OLIVEIRA, L.C. A experiência estética em Dufrenne e Quintás e a percepção de natureza: para uma educação ambiental com bases fenomenológicas. Revista Eletrônica do Mestrado em Educação Ambiental. Rio Grande, RS: v.15, p.196-210, jul./dez. 2005.

MARIN, A. A. A educação ambiental nos caminhos da sensibilidade estética. Revista Inter Ação, v. 31, n. 2, p. 277-290, 2007.

MOREIRA, A. A. A. Espaço do desenho-A educação do educador (O). Vol. 4. Edições Loyola, 1984.

MORIN, A. Saber, ciência e ação/André Morin, Gilles Gadoua, Gérard Potvin; tradução Michel Thiollent. São Paulo: Cortez, 2007. 
NUNES, L. S. R. Educação Ambiental e arte participativa: questões socioambientais através da sensibilidade e criticidade. 2017. IFRJ: Programa de Pós-Graduação Stricto Sensu em Ensino de Ciências - Dissertação (mestrado). 117f.

OSTROWER, F. Criatividade e processos de criação. Petrópolis: Vozes, 1987.

RÊGO, I. D. Ensino de artes e fotografia: um click na educação. 2006. Universidade de Sorocaba. Programa de Pós-Graduação em Educação - Dissertação (mestrado). 83p.

SANTOS, M. 1992: a redescoberta da Natureza. Estudos Avançados, v. 6, n. 14, p. 95-106, 1992.

SIMÕES, M. R. A cidade estilhaçada: Reestruturação econômica e Emancipações Municipais na Baixada Fluminense. 2006. UFF: Programa de Pós Graduação em Geografia - Tese (doutorado). 292p.

TOZONI-REIS, M. F. de C.; TOZONI-REIS, J. R. Conhecer, transformar e educar: fundamentos psicossociais para a pesquisa-ação-participativa em educação ambiental. Reunião anual da ANPEd, v. 27, 2004. 